\title{
Variations nutritionnelles de la capacité lipogénique des tissus adipeux abdominaux chez l'agneau
}

\author{
P Bas, A Rouzeau, M Rigault, P Poissonnet, D Sauvant
}

INRA-INAPG, Laboratoire de Nutrition et Alimentation, 16 rue Claude Bernard, 75005 Paris, France

\begin{abstract}
L'essai décrit a pour but d'étudier les relations entre la densité énergétique du régime et la capacité lipogénique des tissus adipeux (omental, OM et périrénal, PR) de l'agneau en croissance.
\end{abstract}

Deux lots de 6 agneaux de race croisée issue de croisement Suffolk $x$ INRA 401 , sont alimentés, du sevrage $(80 \pm 0,65 \mathrm{j})$ à l'abattage (vers 40-42 $\mathrm{kg}$ de poids vif, i.e. à $131 \pm 2,1 \mathrm{j}$ ), avec une ration complète offerte à volonté. La ration individuelle, pesée quotidiennement, est constituée de foin de luzerne et de concentré $(30 / 70 \% / M S$ : lot $\mathrm{H}$ et $70 / 30 \% / M S$ : lot B). Le concentré est à base d'orge et de tourteau de soja, en proportions telles que les 2 rations soient isoazotées $(2,57 \mathrm{Mcal}$ d'énergie métabolisable, EM, $200 \mathrm{~g}$ protéines brutes, $346 \mathrm{~g}$ amidon $/ \mathrm{kg}$ MS et 2,18 Mcal EM, 193 protéines brutes, $146 \mathrm{~g}$ amidon $/ \mathrm{kg} M S$, respectivement pour les lots $H$ et $B$ ). Dès l'abattage, les dépôts adipeux OM et PR sont pesés et des échantillons sont congelés à $-30^{\circ} \mathrm{C}$ jusqu'à la détermination da la teneur en lipides et des activités de : la glucose6-phosphate déshydrogénase (G6PDH), la malate déshydrogénase (MD), la lipoprotéine lipase (LPL) (Bas, 1992, J Anim Sci, 70, 3857, 3866) et la synthétase des acides gras (FAS) (Halestrup and Denton, 1973, Biochem J, 132, 509-517). Des prélèvements de sang ont été effectués le matin de l'abattage en vue de déterminer la glycémie avec une méthode à l'hexokinase et l'insulinémie par radioimmunologie.

De 11 à 18 semaines d'âge, le niveau moyen d'ingestion d'EM est plus élevé pour le lot $\mathrm{H}$ que pour le lot B (246 vs $207 \mathrm{kcal} \mathrm{EM} / \mathrm{j} / \mathrm{kg}$ P 0.75 , $P<0,01)$, mais les GMQ moyens des 2 lots sont comparables ( 348 vs $315 \mathrm{~g} / \mathrm{j}$, ETR $=48,0 \mathrm{~g} / \mathrm{j}$, $P$ : NS, lot $H$ vs lot $B$ ). De ce fait, l'indice de consommation (EM/kg gain) du lot B est meilleur que celui de $\mathrm{H}(+11,5 \%, \mathrm{P}<0,05)$. La glycémie et l'insulinémie sont plus élevées dans le lot $H(6,11$ vs $5,39 \mathrm{mM} / \mathrm{l}, P<0,01$ et 27,3 vs $13,9 \mu \mathrm{UI} / \mathrm{ml}, P<0,05$, respectivement). Les poids et teneurs en lipides de OM et PR ont tendance à être plus élevés dans $\mathrm{H}$ (OM : 571 vs $505 \mathrm{~g}, 81,4$ vs $80,6 \%$ lipides ; et PR : 307 vs $271 \mathrm{~g}, 84,1$ vs $82,5 \%$ lipides, respectivement pour $\mathrm{H}$ et $\mathrm{B}, \mathrm{P}$ : NS). Dans le tissu $O M$, les activités des 4 enzymes, exprimées par $\mathrm{g}$ de tissu, ne différent pas significativement entre les 2 lots. Cependant, dans le tissu PR, les activités de la FAS, de la G6PDH et de la MD ont tendance à être plus élevées pour le lot $H$ que pour le lot $B$ (175 vs $103, P=0,10 ; 2078$ vs $1512, P<0,05 ; 276$ vs $195 \mathrm{nmol} / \mathrm{min} / \mathrm{g}, P<0,10$, respectivement). Dans $O M$, les activités totales de ces 4 enzymes apparaissent comparables entre les 2 lots, mais dans PR les activités totales de la FAS, de la G6PDH et de la MD semblent plus élevées pour le lot $H(P=0,13, P<0,10$, $P=0,20$ ). Pour l'ensemble des animaux, les valeurs de la FAS, de la G6PDH et de la MD de PR sont corrélées de façon plus étroite avec le niveau d'ingestion d'EM à $S_{-1}(r=0,59$, $P<0,05, r=0,69, P<0,05, r=0,74, P<0,01$, respectivement) qu'avec le niveau moyen d'ingestion d'EM des semaines précédentes. Dans $O M$, les variations de ces enzymes sont liées de façon moins étroite à l'EM à $S_{-1}$ $(r=0,49, P=0,15, r=0,58, P<0,05, r=0,69$, $P<0,05$, respectivement). Dans ces 2 tissus, les corrélations entre ces 3 enzymes et l'insulinémie sont du même ordre que celles observées avec l'EM à $S_{-1}$.

En conclusion, les différences de densité énergétique de la ration ont eu peu d'influence sur les vitesses de croissance. Par contre, les activités lipogéniques de la FAS et des déshydrogénases paraissent influencées par le niveau d'ingestion d'EM des jours précédents. 